\title{
Sodium nitroprusside: theory and practice
}

\author{
IAN R. VERNER \\ M.B.Ch.B., F.F.A.R.C.S., D.A. \\ The Middlesex Hospital, London
}

\begin{abstract}
Summary
Sodium nitroprusside, by a peripheral vasodilator action, is a powerful hypotensive drug. In contrast to established agents, its hypotensive action is accompanied by an unchanged or augmented cardiac output. Intravenous administration of sodium nitroprusside rapidly produces a profound and controllable hypotension. Normotension is swiftly restored by ceasing to infuse the agent, and antidotes are unnecessary. Its attributes make it especially suitable for neurosurgical anaesthesia, and although free cyanide is liberated during biotransformation, side effects are virtually absent provided that dosage is reasonable. Special contraindications to its use are hypothyroidism and altered cobalamin metabolism.
\end{abstract}

Sodium nitroprusside was discovered in 1893 by Playfair, and by 1929 Johnson had outlined its basic pharmacology. By 1955 Page et al. had shown that it could be used to treat hypertensive patients, and that even with prolonged administration its toxic effects were minimal. It was not until 1970 that the first definitive paper on its use to produce hypotension during anaesthesia appeared (Taylor, Styles and Lamming, 1970). During the following 3 years numerous papers describing its use during anaesthesia have appeared, all of which have testified to the efficiency and lack of side effects of the agent. Sodium nitroprusside is now established as an effective and malleable hypotensive agent, and is the drug of choice in many centres. It is, however, still a relatively untried drug, and its potential toxicity should be constantly born in mind. Doubtless its possible lethal effects delayed its adoption by anaesthetists, but experience so far has shown that, provided care is taken in the use of the drug, it is remarkably free from deleterious effects.

\section{Pharmacology}

Sodium nitroprusside $\left(\mathrm{Na}_{2} \mathrm{Fe}^{++}(\mathrm{CN})_{5} \mathrm{NO} .2 \mathrm{H}_{2} \mathrm{O}\right)$ forms reddish-brown crystals which are soluble in water. In solution it is relatively stable, resisting oxidation at a neutral or slightly acidic $\mathrm{pH}$. The structural unit is the nitroprusside radical, which consists of one iron atom linked to one nitrosyl and five cyanide groups. The basic units link together to form a lattice which contains the sodium and water molecules. The exact mode of action of the compound is unknown, but since many nitrites have vasodepressor actions, it is assumed that the ironnitrosyl group is the active part of the molecule. It has been estimated that the nitrosyl group is between 30 and 1000 times more powerful than nitrites (Johnson, 1929). The primary action of sodium nitroprusside is smooth muscle relaxation; this action is direct and most readily seen in the vascular system (Johnson, 1929; Page et al., 1955). Intravenous sodium nitroprusside rapidly produces a profound hypotension which is readily reversible and is not accompanied by tachyphylaxis. Recent controlled studies by Wildsmith et al. (1973) ando Styles, Coleman and Leary (1973) have delineated the cardiovascular changes which accompanyo sodium nitroprusside-induced hypotension both in anaesthetized and non-anaesthetized humans. Both investigations are in close agreement. The lowered arterial pressure was accompanied by a profound fall in both central venous pressure and peripheral resistance, the heart rate was slightly elevated and the cardiac output was either unchanged or else rose slightly. Changes in stroke volume were neither consistent nor significant. It is important to note that the hypotension was not accompanied by a reduction in cardiac output, for in this respect sodium nitroprusside differs from other hypotensive agents such as halothane or ganglion blocking agents. The pharmacodynamics of sodium nitroprusside would seem to be such that any improvement in operating conditions is achieved not by a reduction in tissue perfusion, but rather by a reduction in arterial pressure. Provided that arterial oxygenation is satisfactory, combination of an unchanged or enhanced cardiac output coupled with a decreased peripheral resistance means that tissue oxygen availability will be adequate even under hypotensive conditions.

\section{Heart rate}

Early reports of sodium nitroprusside hypotension indicated a variable cardiac response. Schiffmann and Fuchs (1966), Jones and Cole (1968) and Taylor et al. (1970) all stated that the heart rate could 
remain unchanged, slow or accelerate. The more recent studies have shown that there is normally a $20 \%$ increase in heart rate during the hypotensive phase. The rarity of a markedly elevated pulse rate following upon the use of sodium nitroprusside undoubtedly plays a part in the ease with which it can produce satisfactory operating conditions. In a few instances a pronounced tachycardia will be seen after sodium nitroprusside has been given. In such circưnstances hypotension may be difficult to establish, but the rate can be slowed by administering $\beta$-adrenergic blocking drugs.

\section{Myocardial function}

No adverse effects of sodium nitroprusside upon myocardial function have been reported. Franciosa et al. (1972) studied the effects of sodium nitroprusside upon cardiac output and left ventricular function in a series of patients who had suffered recent myocardial infarction. They found that, with a mild degree of hypotension, left ventricular filling pressure fell and cardiac output was enhanced. From these observations and the condition of their patients they concluded that the coronary circulation was not embarrassed by the procedure.

\section{Effects on other organs}

Kidneys. Johnson (1929) observed dilatation in the isolated and perfused renal artery on exposure to sodium nitroprusside, which was accompanied by increased renal perfusion. The renal haemodynamic effects in both dogs and humans were studied by Page et al. (1955). In dogs they found that both renal perfusion pressures and renal vascular resistance were lowered. Para-amino hippurate and creatinine clearance values were largely unchanged, as was the tubular reabsorptive capacity for glucose. In human beings similar results were obtained, and it was noted that in both species the hypertensive were more sensitive to the effects of sodium nitroprusside than were the normotensive. Clear evidence of a vasodilator action upon the renal vasculature was obtained radiographically by Moraca et al. (1962).

Intestines and uterus. Johnson (1929) found that sodium nitroprusside inhibited contractions of isolated and perfused strips of muscle excised from the uterus and intestines. However, Page et al. (1955) found that nitroprusside did not relax the virgin or pregnant uterus of rabbits or the duodenum of dogs even when given in markedly hypotensive dosage.

Bronchial musculature. It might be expected that sodium nitroprusside would relax bronchial musculature and Johnson (1929) suggested its use therapeutically to relieve bronchoconstriction. There appear to be no studies of the actions of sodium nitroprusside on the bronchial tree. Personal experience indicates that though sodium nitroprusside can relieve bronchoconstriction occurring during general anaesthesia, objective improvement does not occur until arterial tension is grossly depressed. It would therefore seem that, at least unaided, sodium nitroprusside has little place in the therapy of bronchoconstriction.

\section{Combination with other drugs}

Since sodium nitroprusside acts directly upon the smooth muscle of vessel walls, it is to be expected that agents which reduce the muscle tone will augment the hypotensive effects of nitroprusside. Page et al. (1955) observed that many ganglioplegic and $\alpha$-adrenergic blocking drugs substantially augmented the hypotensive actions of sodium nitroprusside in animals. A similar picture is seen in human beings. Patients who have received $\alpha$-adrenergic blocking agents are markedly sensitive to sodium nitroprusside, and the administration of ganglion blockers before or after an infusion of sodium nitroprusside greatly increases the response to the latter. Drugs which reduce cardiac output (e.g. halothane or $\beta$ adrenergic blockers) also augment its hypotensive action. Conversely, the inhalation of $15-20 \%$ carbondioxide was shown to decrease the hypotension of sodium nitroprusside (Page et al., 1955).

\section{Metabolism and toxicity}

The evanescent action of sodium nitroprusside may be attributed to its rapid bio-transformation. The iron atom of the nitroprusside radical reacts with free sulphydryl groups found in erythrocytes, and releases cyanide radicals. This reaction is nonenzymatic, and its slow time course precludes the release of cyanide from being the mechanism of action of nitroprusside. The free cyanide radicals are then linked enzymatically to sulphydryl groups, forming thiocyanate. The enzyme, which is present in human erythrocytes and liver, was discovered and named rhodanese by Lang (1933). The ending 'ese' indicates that the enzyme is responsible for an irreversible reaction. The observation that the chronic administration of thiocyanate to human beings was followed by a rise in the serum levels of cyanide cast doubts upon the irreversibility of the reaction. Goldstein and Rieders (1953) found that the reaction was indeed irreversible but that the conversion of thiocyanate to cyanide was under the control of yet another enzyme present in human red cells. This enzyme, thiocyanate oxidase, gives a yield of about $1 \%$ cyanide from thiocyanate over a period of $1 \mathrm{hr}$. Optimum conditions for its action are a $\mathrm{pH}$ of 7.4 and a temperature of $40^{\circ} \mathrm{C}$. In essence, therefore, cyanide radicals are converted to thiocyanates under the influence of rhodanese, and some thiocyanate is reconverted to cyanide by thiocyanate oxidase. Such an interconversion was observed by 
Boxer and Richards in 1952. It should be appreciated that the administration of either nitroprusside or thiocyanate to humans, especially if prolonged, may lead to an accumulation of cyanide in the body. The possibility of cyanide intoxication after nitroprusside or thiocyanate therapy has naturally received considerable attention. Page et al. (1955) administered nitroprusside orally to chronic hypertensive patients for periods of 6 weeks to 2 years. Thiocyanate levels in the blood were found to rise, especially if renal function was impaired. Toxic symptoms included fatigue, nausea, loss of appetite and weakness. Thiocyanate levels of between 8 and $12 \mathrm{mg} / 100 \mathrm{ml}$ blood were found to be unaccompanied by toxic effects. Both Goldstein and Rieders (1953) and Pines and Crymble (1952) estimated blood cyanide levels after the acute and chronic administration of thiocyanate. Cyanide levels were always considerably below the $0.34 \mathrm{mg} / 100 \mathrm{ml}$ blood levels stated by Gettler and Baine (1958) to be the minimum fatal concentration. Anaesthetic literature reveals no occasions on which excessive cyanide levels have been found to result from the acute administration of sodium nitroprusside. Cole (personal communication) has found blood cyanide levels often to be unrecordable after sodium nitroprusside hypotension, but has cautioned that present methods of cyanide estimation may be inadequate. It is certain that some fatalities have occurred following nitroprusside administration. One factor is common to all the known cases, namely that large amounts of nitroprusside have been infused. In common with other agents whose detoxification relies upon enzymatic action the possibility of deficient or atypical enzymes occurring in human beings should always be borne in mind.

A further toxic action of nitroprusside has been described by Nourok et al. (1964). Thiocyanates are effective antithyroid agents, and the symptoms of thiocyanate poisoning resemble hypothyroidism in many respects. Nourok and his associates described a case of hypothyroidism occurring after prolonged nitroprusside therapy, and gave evidence that nitroprusside (as well as thiocyanate) may have an antithyroid action. Obviously, nitroprusside should be administered to hypothyroid individuals with caution.

It is reassuring to note that many investigators have commented upon the absence of side-effects after using nitroprusside to induce hypotension for brief periods.

\section{Preparation of solutions}

Pharmaceutical preparations of sodium nitroprusside are not currently available, and hospital pharmacies must therefore prepare their own stock solutions. Analytical grade crystals are dissolved in distilled water with a $\mathrm{pH}$ of approximately $5 \cdot 0$, to make a $10 \mathrm{mg} / \mathrm{ml}$ solution. Heat sterilization will destroy the solution, which is cold sterilized by passage through a membrane filter $(0.22 \mu)$ and stored in sterilized $5 \mathrm{ml}$ ampoules. If stored at a temperature of $4^{\circ} \mathrm{C}$ the shelf life of the solution will be approximately 3 months. Oxidative decomposition of the solution is shown by a colour change from light reddish-brown to deep blue. On no account should any solution showing a colour change be used. The basic working solution of sodium nitroprusside is obtained by adding $5 \mathrm{ml}$ of stock solution of $500 \mathrm{ml} 5 \%$ dextrose, making a $0.01 \%$ solution. Weaker $(0.005 \%$ or $0.002 \%)$ working solutions may be employed for frail subjects, whilst more robust individuals may require stronger working solutions of $0.02 \%$ or even $0.04 \%$.

\section{Technique of inducing hypotension with sodium nitroprusside}

Before inducing hypotension a stable state of general anaesthesia should be established. The exact anaesthetic technique is largely immaterial, and ventilation can be either spontaneous or controlled. It is helpful if the anaesthetic technique is 'self maintaining' in so far as is possible, for satisfactory hypotension with nitroprusside demands continuouse concentration. For this reason, endo-tracheal intubation is virtually mandatory and techniques involving frequent injections of anaesthetic agents are least suitable. As with other hypotensive procedures, a reduction in the $V_{D} / V_{T}$ ratio may be expected and it is therefore important to ensure an adequate concentration $(>40 \%)$ of oxygen in the inspired gases. The anaesthetic agents should bias towards the hypotensive state, for the dose of nitroprusside can then be kept to a minimum. Basic anaesthesia with nitrous oxide, oxygen and halothane has proved to be a suitable technique.

It is essential to monitor the arterial blood pressure. Two methods have the necessary sensitivity and reliability, namely oscillotonometry and direct arterial cannulation. The invasive technique should be employed when first using nitroprusside, for a continuous recording will give early warning of changes in arterial pressure. With experience, oscillotonometry becomes an acceptable substitute; it is quicker to set up, mechanically more reliable and obviates the morbidity associated with arterial puncture. The blood pressure cuff should not be placed around an arm which is receiving a nitroprusside-containing drip, for inflation of the cuff will then retard the rate of infusion. Even transient interruptions of flow will lead to blood pressure variations. All patients receiving nitroprusside require two separate intravenous infusions. One, for fluids and blood, is set up once anaesthesia has been induced. 
A wide-bore (14 gauge) cannula should be used, for this infusion may be required to elevate blood pressure rapidly. The other, kept exclusively for nitroprusside, is placed in situ immediately it is required to hypotense the patient. When the required working solution has been made up, an intravenous administration set is inserted into the bottle and the giving set filled with the working solution. The drip set should never be filled with intravenous infusion fluid and the stock solution then added to the intravenous bottle, for in this way a nitroprussidefree fluid 'dead space' will exist in the tubing. In these circumstances there will be uncertainty as to when hypotension will commence.

The required working solution is clearly labelled, and then connected directly to a small bore intravenous cannula. The practice of inserting a nitroprusside infusion into a side arm of the main infusion should be avoided. Sodium nitroprusside is an extremely potent agent, and even the small amount inside an intravenous cannula is capable of causing a precipitous fall of blood pressure. Hypotension can be conducted with more certainty and safety if the nitroprusside infusion is kept entirely separate from the normal infusion.

Precise control of the nitroprusside infusion is important, and several methods are possible. A normal infusion set with a standard control has the advantage that no special equipment is required. However, standard drip controls may be too insensitive, especially at slow drip rates. More precise regulation can be effected leaving the drip control set in one position and raising or lowering the bottle containing the infusion to alter administration rates. A further improvement is the substitution of an oversize drip control for that supplied with the drip set. A microdrip infusion system, such as is used for paediatric fluid administration, will give very fine control of infusion rates. Suitable sets have a small drip needle in the infusion chamber, the small droplet size allowing very slow rates of infusion. Lastly, electronic drip-counting mechanisms or infusion pumps have been used. Whilst these mechanisms allow a very steady infusion rate to be maintained almost indefinitely, they suffer from the disadvantages of expense, mechanical unreliability and may have too slow a response time. Once confidence has been obtained in the use of the agent it will be found that the normal drip set with standard control is satisfactory. The advantages of ready availability and reliability will be obvious.

To induce hypotension the nitroprusside infusion is commenced at a rate of $15-30$ drops $/ \mathrm{min}$. Blood pressure should be monitored continuously. Arterial pressure will usually start falling immediately or at least within 2 min of commencing the infusion, but in rare cases where hypotension is refractory, the nitroprusside infusion should be progressively speeded up until an effect is observed. Once hypotension develops the rate of fall of pressure should be carefully noted. A gradual fall can be allowed to continue unchecked until the desired level of tension is reached, when the drip rate is then slowed to the level required for maintenance. However, if there is a rapid and progressive fall in blood pressure, the drip rate should be checked long before the desired tension is reached. For the beginner using nitroprusside, and before the potentialities of the agent are realized, too rapid a fall in blood pressure is frequently produced. Slowing or ceasing the infusion then results in an equally rapid rise which is counteracted by restarting the infusion. This results in a 'see-saw' pressure level, and it may be 5 to $10 \mathrm{~min}$ before a stable level of hypotension is reached. This can usually be avoided by inducing hypotension more slowly from the beginning.

Should the blood pressure fall too low, normotension can be reinstated by stopping the infusion. In most cases recovery of arterial pressure commences within $15 \mathrm{sec}$. Recovery is rapid and progressive, being substantially complete within 2-5 min. It is in the extreme transience of its action that the safety of nitroprusside lies. Antidotes are not required, and to boost recovery it is merely necessary to infuse rapidly some $200 \mathrm{ml}$ of normal intravenous fluids. The importance of a separate hypotensive infusion is reiterated, for under conditions of extreme hypotension the infusion of even the small amount of nitroprusside contained within an intravenous cannula ahead of a bolus of normal intravenous fluid may be sufficient to cause a serious fall of pressure. It should be appreciated that in most patients there is no lower limit to the hypotension which may be achieved with nitroprusside. Usually the level of hypotension is directly proportional to the rate of infusion, a fact which can be used to advantage, for blood pressure can be taken down in a 'step-wise' fashion to the target level. The speed and ease with which arterial pressure levels may be changed during the course of an anaesthetic is the most attractive feature of this drug, and in this respect it outmatches any other hypotensive agent.

If meticulous attention is paid to infusion rates and blood pressure levels, controlled and effective hypotension can be produced in almost all patients. Two types of patient may present difficulties. In one there may be an increased sensitivity to the drug. Patients in this category are commonly elderly or infirm, and it is here that the weaker working solutions should be employed. In contrast, others will be remarkably resistant. Almost invariably these are robust young adults. With such patients satisfactory hypotension may not be established even by infusing normal strength solutions at rates of between 120 and 
$180 \mathrm{drops} / \mathrm{min}$. Such infusion rates carry with them the danger of too great a fluid load being delivered to the patient. Here, either the concentration should be increased (which will diminish the fluid load), or agents which augment the vaso-depressor actions of nitroprusside should be added (which will reduce the amount required). Hence, increasing the inspired concentration of halothane or adding small amounts of ganglion-blockers will enable a more satisfactory hypotension to be achieved. After such measures the recovery of normotension may be slightly prolonged. Though true resistance to nitroprusside is extremely rare, there are great variations in sensitivity to this agent. The total amount necessary to effect profound hypotension for periods of between 1 and $3 \mathrm{hr}$ can range between 5 and 200 $\mathrm{mg}$, and infusion rates varying between 15 and one hundred and twenty drops/min may be required. If it becomes obvious that excessive amounts are being infused, potentiating agents should be added. Until more information is available about the enzymatic metabolism of cyanide in man, large amounts of sodium nitroprusside should not be administered with abandon.

\section{Restoration of normotension}

Normotension should normally return within 5 min of ceasing the infusion.

This is to be expected even if hypotension has been prolonged or the total dosage large. Should a slower restitution be required, it may be obtained by progressively retarding the rate of infusion. Once nitroprusside is discontinued, any delay in the return of normotension can be attributed to either the effects of anaesthesia or a deficiency in blood volume, and the appropriate remedial steps can be taken. When it is certain that further hypotension will not be required, the nitroprusside infusion should be securely clamped or removed from the patient to avoid the possibility of inadvertent hypotension.

\section{Indications for use}

Sodium nitroprusside is a suitable agent for use in most cases where hypotension is required. Its special features are potency, rapid action and extreme controllability, allowing minute by minute control of blood pressure. Pre-eminently it is the agent of choice during neurosurgery, where blood pressure may need to be altered rapidly to meet varying surgical conditions. For example, the surgical approach to an intracranial aneurysm may be conducted under slight or moderate hypotension, and the blood pressure then lowered profoundly for surgery of the aneurysmal sac. Once definitive surgery of the lesion is complete, the blood pressure may be rapidly restored to normal levels and the adequacy of treatment assessed. Should further surgery be necessary, the blood pressure may again be lowered within minutes to a more useful level.

Siegel, Moraca and Green (1971) have commented favourably upon the use of nitroprusside for intracerebral surgery, finding an improvement in the morbidity and mortality of patients with Grade I or II aneurysmal lesions. The malleability of the drug is a great advantage should uncontrollable haemorrhage develop during this operation. Whilst under ganglion blocking agents a considerable delay ensues before normal tone returns to the cardiovascular system, with sodium nitroprusside normal tone returns soon after the infusion has stopped, and the disastrous effects of hypovolaemia with hypotension can thereby be avoided.

The surgery of pheochromocytomata is also best carried out under nitroprusside hypotension, Katz and Wolf (1971). Patients with these tumours will normally have received treatment by $\alpha$ - and $\beta$ adrenergic blocking drugs, and will often be remarkably sensitive to the hypotensive effects of nitroprusside. Hypertension resulting from manipulation of the tumour can be remarkably easily and swiftly annulled. When the pheochromocytoma has been excised discontinuing the nitroprusside will lead to a restoration of vascular tone within minutes and if hypertension does not return, then it may be assumed that surgery has been successful.

Nitroprusside may, of course, be used in most situations where hypotension is indicated. In only one instance, namely when a more gradual return of blood pressure is required, can other agents be used to more advantage. It appears likely that increasing experience with this agent will lead to its wider use because of the rapidity and certainty with which blood pressure can be lowered. Its use need not be limited to anaesthesia for it is valuable in severe hypertensive crises outside the operating theatre. Should vasodilation be thought to be helpful during angiography, then it will rapidly and transiently produce the desired conditions. The ephemeral action of this drug is perhaps its most attractive feature. Once hypotension has been discontinued, there are no long-lasting sequelae (vasomotor or smooth muscle paralysis) and it is the only drug which can produce hypotension for exactly the period required.

\section{Contraindications}

Contraindications to hypotension are outside the scope of this article, but they obviously apply equally to nitroprusside and to other hypotensive agents. A contraindication to nitroprusside is hypothyroidism. According to the severity of the disease this will be either relative or absolute, but in any case prolonged exposure should never be permitted. The literature pertaining to the use of nitroprusside is remarkably free of contraindications or reports of deleterious 
sequelae. Nevertheless it cannot be overstressed that caution should always be exercised when using a relatively new agent, and if the speed of administrasion or the total amount given ever begins to cause anxiety it should be remembered that discretion should always precede valour.

\section{References}

Boxer, G.E. \& Richards, J.C. (1952) Studies on the metabolism of the carbon of cyanide and thiocyanate. Archives of Biochemistry, 39, 7.

Franciosa, J.A., Guiha, N.H., Limas, C.J., Rodriguera, E. \& CoHN, J.N. (1972) Improved left ventricular function during nitroprusside infusion in acute myocardial infarction. Lancet, i, 650.

Gettler, A.C. \& Baine, J.C. (1958) Toxicology of cyanide. American Journal of Medical Sciences, 195, 182.

Goldstein, F. \& Rieders, F. (1953) Conversion of thiocyanate to cyanide by an erythrocytic enzyme. American Journal of Physiology, 173, 287.

Johnson, C.C. (1929) The actions and toxicity of sodium nitroprusside. Archives of Internal Pharmacodynamics, 35, 480.

JoNes, G.O.M. \& Cole, P. (1968) Sodium nitroprusside as a hypotensive agent. British Journal of Anaesthesia, 40, 804.

KATZ, R.L. \& Wolf, C.E. (1971) Highlights of Clinical Anaesthesiology, p. 56. Harper and Row: New York.

LANG, K. (1933) Die Rhodanbildung im Tierkorper. Biochemische Zeitschrift, 259, 243.
Moraca, P.P., Elmars, M.B., Hale, D.E., Wasmuth, C.E. \& Poutasse, E.F. (1962) Clinical evaluation of sodium nitroprusside as a hypotensive agent. Anesthesiology, 23, 193.

Nourok, D.S., Glassock, R.J., Solomon, D.H. \& MaXWELL, M.H. (1964) Hypothyroidism following prolonged sodium nitroprusside therapy. American Journal of Medical Sciences, 248, 129.

Page, I.H., Corcoran, A.C., Dustan, H.P. \& Koppanyi, T. (1955) Cardiovascular actions of sodium nitroprusside in animals and hypertensive patients. Circulation, 11, 188.

Pines, K.L. \& CRYMble, M.M. (1952) In vitro conversion of thiocyanate to cyanide in presence of erythrocytes. Proceedings of the Society for Experimental Biology and Medicine, 81, 160.

SchiffmanN, H. \& Fuchs, P. (1968) Controlled hypotension effected by sodium nitroprusside. Acta anaesthesiologica Scandinavica, supp. 23, 704.

Siegel, P., Moraca, P.P. \& Green, J.R. (1971) Sodium nitroprusside in the surgical treatment of cerebral aneurysms and arteriovenous malformations. British Journal of Anaesthesia, 43, 790.

Styles, M., Coleman, A.J. \& Leary, W.P. (1973) Some haemodynamic effects of sodium nitroprusside. Anesthesio$\log y, 38,173$.

TAYlor, T.H., Styles, M. \& Lamming, A.J. (1970) Sodium nitroprusside as a hypotensive agent in general anaesthesia. British Journal of Anaesthesia, 42, 859.

Wildsmith, J.A.W., Marshall, R.L., Jenkinson, J.L., MAcRAe, W.R. \& ScotT, D.B. (1973) Haemodynamic effects of sodium nitroprusside during nitrous oxide/ halothane anaesthesia. British Journal of Anaesthesia, 45, 71 .

\section{Addendum}

Since submission of this manuscript an important communication on the metabolism of sodium nitroprusside has been published [Vesey, C.J., Cole, P.V., Linnell, J.C. and Wilson, J. (1974) Some metabolic effects of sodium nitroprusside in man. British Medical Journal, 2, 140.] The authors found a highly significant rise in plasma cyanide levels after sodium nitroprusside was infused during major orthopaedic surgery. Plasma vitamin $B_{12}$ and methylcobalamin levels were simultaneously decreased. In one instance, after prolonged administration of sodium nitroprusside, erythrocyte cyanide concentration rose, but was reduced by intravenously administered hydroxocobalamin.

Although no adverse effects on the patients are reported, the authors caution that sodium nitroprusside may be contraindicated for patients with low plasma $\mathrm{B}_{12}$ levels, liver disease, or Leber's optic atrophy, and suggest the prophylactic use of hydroxocobalamin whenever sodium nitroprusside is to be used. 